\title{
AS ABORDAGENS DE CORPO, GÊNERO E SEXUALIDADES NO PROJETO POLÍTICO PEDAGÓGICO EM UM COLÉGIO ESTADUAL DE ARACAJU, SE
}

\author{
A. F. DIAS* ${ }^{*}$ D. A. DE OLIVEIRA
Universidade Federal de Sergipe
diasalfrancio@hotmail.com \\ Artigo submetido em maio/2015 e aceito em junho/2015 \\ DOI: $10.15628 /$ holos.2015.3084
}

\section{RESUMO}

O objetivo deste texto é analisar como as temáticas do corpo, gênero e sexualidades estão colocadas no Projeto Político Pedagógico em um colégio público estadual, localizado na cidade de Aracaju (SE). Adotamos uma perspectiva pós-crítica e pós-estruturalista, problematizando os processos de significação e como eles influenciam a produção do conhecimento e as relações sociais, a partir das leituras dos autores: Carvalho (2009), Foucault (2014), Louro (2010), Scott
(1995), Butler (2010). Metodologicamente, desenvolvemos uma abordagem qualitativa, a partir da análise documental numa perspectiva cultural e social. Verificamos que as temáticas do corpo, gênero e sexualidades são introduzidas superficialmente, podendo estar ligadas à falta de familiaridade, bem como à ausência na formação inicial e continuada dos agentes escolares.

PALAVRAS-CHAVE: Corpo, Gênero, Projeto Político Pedagógico, Sexualidades.

\section{BODY, GENDER AND SEXUALITIES APPROACHES IN THE POLITICAL-PEDAOGICAL PROJECT IN A STATE SCHOOL IN ARACAJU, SE}

\section{ABSTRACT}

The aim of this text is to analyse how the themes of body, gender and sexuality have been positioned in the Political-Pedagogical Project in a state school, located in the city of Aracaju (SE). We have adopted a post-critical and post-structuralist perspective, problematizing the processes of signification and how they influence the knowledge production and social relations, from the authors' readings: Carvalho (2009), Foucault (2014),
Louro (2010), Scott (1995), Butler (2010) Methodologically, we have developed a quantitative approach, from the documental analysis in a cultural and social perspective. We have verified that body, gender and sexuality themes are introduced superficially, causing to be linked to lack of familiarity, as well as to the absence of initial and continued education formation of the school agents.

KEYWORDS: Body, Gender, Political-Pedagogical Project, Sexualities. 


\section{APRESENTAÇÃO}

A desconstrução de conceitos que hierarquizam os relacionamentos e mantêm à margem os grupos socialmente discriminados tem ganhado relevância em diversas áreas do conhecimento, principalmente nas Ciências Humanas, a partir de uma perspectiva questionadora e promotora da inclusão que os estudos de corpo, gênero e sexualidade têm abarcado. No campo educacional não é diferente; o meio acadêmico, através desses estudos, vem viabilizar a discussão do espaço escolar, como um local multicultural, desfazendo o formato padrão da educação que historicamente tem neutralizado a diferença.

O cotidiano escolar é dinâmico, fluido e com experiências inesperadas, que se inserem nas práticas pedagógicas através do currículo "oculto" ou "informal", permeando nas aulas e no cotidiano escolar questões diversas. Os programas das disciplinas escolares e a própria gestão organizacional, muitas vezes, não se apropria dessas questões, desprezando-as; porém, quando em situações adversas, elas aparecem.

A introdução das temáticas como cultura, multiculturalismo, corpo, diversidade de gênero e sexual, desigualdade, equidade, diferença, classe, relações étnicas, geração nos currículos formais escolares, na gestão escolar e no Projeto Político Pedagógico das instituições de ensino pode desenvolver uma prática pedagógica mais tolerante às diferenças. Como esses são os definidores do processo de ensino, das práticas escolares, do papel dos/as docentes e da própria função de educação que as instituições desenvolvem, faz-se necessário ampliar o olhar sobre essas temáticas ou dar uma maior visibilidade dentro das metas e estratégias para serem alcançadas no decorrer do ano letivo.

Nesse sentido, cabe questionar como as abordagens de corpo, gênero e sexualidades estão postas no Projeto Político Pedagógico de uma instituição pública de ensino médio? Qual o lugar dessas temáticas nos objetivos, metas e metodologias do Projeto Político Pedagógico? Tais questionamentos serviram como fio condutor para a análise da inclusão e a importância da discussão dessas temáticas na escola em todo processo de ensino, ou seja, a sua transversalidade no Projeto Político Pedagógico, no currículo escolar e nas práticas pedagógicas dos/das docentes.

Neste texto trazemos alguns resultados iniciais da pesquisa desenvolvida no Programa de Pós-graduação em Educação da Universidade Federal de Sergipe, intitulada "A inclusão da perspectiva de gênero na formação inicial e continuada de professores da educação básica", financiada pela CAPES. Adotamos, portanto, uma perspectiva pós-crítica e pós-estruturalista, problematizando os processos de significação e como eles influenciam a produção do conhecimento e as relações sociais, a partir das leituras dos autores Carvalho (2009), Foucault (2014), Louro (2010), Scott (1995) e Butler (2010).

A opção metodológica recaiu na abordagem qualitativa, por considerar a necessidade de um conjunto de técnicas interpretativas para expressar o sentido dos fenômenos sociais e a compreensão dos significados das ações e relações humanas (DENZIN, 2006). Consideramos também que a pesquisa qualitativa está mais próxima das perspectivas de análise dos estudos culturais - as imagens de gênero se constituem como uma de suas vertentes analíticas -, bem como os estudos de gênero inserem-se no campo do multiculturalismo, tendo como pauta principal de discussão, a ambiguidade da identidade/diferença (WOODWARD, 2007; HALL, 2003). 
Como estratégia de coleta de dados, elegemos a análise documental, com vistas a produzir conhecimento relativo ao objeto, numa perspectiva cultural e social.

Inicialmente, discutimos as abordagens sobre corpo, gênero e sexualidades na escola e no currículo escolar. Posteriormente, apresentamos os principais resultados da pesquisa com a análise do Projeto Político Pedagógico.

\section{AS ABORDAGENS SOBRE CORPO, GÊNERO E SEXUALIDADES NA ESCOLA}

As características atribuídas aos homens e às mulheres devem ser questionadas e desnaturalizadas, pois fazem parte de um processo histórico de construção. Os estudos de gênero surgem como uma ferramenta analítica e política que permite compreender "o caráter fundamentalmente social das distinções baseadas no sexo" (SCOTT, 1995, p. 72). Pretendemos problematizar as formas pelas quais o binarismo homem/mulher, pautado no aspecto biológico, foi construído e disseminados nas relações sociais. As formas de representação dos sentidos e significados que atribuímos aos papéis e lugares masculinos e femininos possibilitaram o surgimento de masculinidades e feminilidades demarcadas pela hetoronormatividade. Modos de vestir, comportar, agir, pensar são determinados para homens e mulheres de forma diferente, como se o sexo já possibilitaria o poder para os homens e a submissão às mulheres. É justamente alguns desses aspectos e, tantos outros, que os estudos de gênero têm questionado.

[...] obriga aquelas/es que o empregam a levar em consideração as distintas sociedades e os distintos momentos históricos de que estão tratando. Afasta-se de (ou se tem a intenção de afastar) proposições essencialistas sobre os gêneros; a ótica está dirigida para um processo, para uma construção, e não para algo que exista a priori. $O$ conceito passa a exigir que se pense de modo plural, acentuando que os projetos e as representações sobre mulheres e homens são diversos. Observa-se que as concepções de gênero diferem não apenas entre as sociedades ou os momentos históricos, mas no interior de uma dada sociedade, ao se considerar os diversos grupos (étnicos, religiosos, raciais, de classe) que a constituem (LOURO, 2010, p. 23).

Tal perspectiva enseja a necessidade de perceber a construção cultural do gênero e desmitificar o poder masculino que tornou a mulher o segundo sexo, ${ }^{1}$ colocando-a na condição de submissa, restringindo-a ao espaço privado. Para Louro, temos que abandonar os discursos essencialistas de gênero, ligados prioritariamente ao aspecto dicotômico sexo/gênero, para pensálo a partir da cultura. Os significados que temos sobre homens e mulheres podem ser modificados pelas relações sociais demarcadas pelo tempo e espaço. Nesse sentido, ao falarmos de gênero temos que levar em consideração a fluidez das representações e os significados que homens e mulheres atribuem aos seus corpos, seus desejos, a sua sexualidade. Nesse cenário historicamente desigual, os estudos de gênero e sua interseção com os estudos sobre corpo, sexualidades, étnicosraciais, religião e geracionais contribuem para a diminuição das assimetrias de poder e para o aumento da equidade.

O gênero é uma categoria arquitetada a partir de construções culturais, sociais e psicológicas e não biologicamente definido, ele é uma categoria de análise.

${ }^{1}$ Ver mais detalhes em O Segundo Sexo (1949) de Simone de Beauvoir. 
Estudar as categorias de gênero é pensar como elas são estruturadas, fazer esse exame é estabelecer uma relação tanto como social como simbólica. Na análise das desigualdades de gênero, não podemos abstrair as desigualdades de classe, etnicidade e raça que tornam ainda mais dramáticas as vivências dos indivíduos e, mais especificamente, das mulheres (CRUZ, 2014, p. 10).

Essas discussões implicam detectar que os estudos de gênero não abarcam apenas a submissão feminina, eles permitem compreender todas as vivências a que são submetidos os indivíduos, e questionar as desigualdades nas relações, seja ela concreta ou simbólica. Permitem, ainda, compreender os aspectos históricos que estão imbricados nessa relação, desfazendo uma visão que neutraliza as diferenças, silenciando os discursos que ficam a margem do que é instituído como padrão universal. No processo de construção de gênero, as relações se estabelecem através de um polo de poder em que o padrão masculino é um "parâmetro universal" (BOURDIEU, 1999, p. 17), pondo os homens num lugar privilegiado nas relações sociais no exercício de poder.

\begin{abstract}
O exercício do poder não é simplesmente uma relação entre "casais" individuais ou coletivos; é um modo de ação de alguns sobre os outros. O que é dizer, desde já, que não existe algo chamado o Poder, o poder, que existiria universalmente, em forma massiva ou difusa, concentrado ou distribuído. Somente existe o poder que exercem "uns" sobre os "outros". O poder só existe em ato, no entanto, desde logo se inscreve em um campo de possibilidades dispersas, apoiando-se sobre estruturas permanentes. Isto também significa que o poder não é uma espécie de consentimento. Em si mesmo não é renúncia a uma liberdade. Transferência dos direitos detidos para alguém lhe representar? ( $O$ que não impede que $O$ consentimento possa ser uma condição para a existência ou manutenção da relação de poder); a relação de poder pode ser o efeito de um consentimento permanente ou anterior, mas não pela natureza da manifestação de um consenso. (FOULCAULT, 1988, p. 14).
\end{abstract}

As relações de poder permeiam toda trama normativa de um discurso que tem por objetivo hierarquizar, subordinar e excluir. Ganham cada vez mais espaço através dos dispositivos que são representados na política, na religião, nas ciências e em diversas instituições, controlando de forma cada vez mais ampla as populações e difundindo uma relação de proximidade ao padrão instituído. Nesse sentido, com o objetivo de desconstruir tais padrões, os estudos culturais contribuem com novas formas de pensar o sujeito, entendendo como a produção da cultura e como os sistemas dominantes dão significado as experiências subjetivas e vivência do cotidiano.

Sendo a escola um espaço de socialização, um dispositivo de poder, ela tem sido uma ferramenta para manutenção de ideologias. Bourdieu (1999) afirma que o currículo está baseado na cultura dominante. É necessário compreender como as ideologias dominantes estiveram presentes no currículo ao longo da história, como as pessoas se percebiam e construíam suas identidades fixas de subordinação e não questionavam seus espaços, pois "[...] é através do vínculo entre conhecimento, identidade e poder que os temas da raça e da etnia ganham seu lugar no território curricular" (SILVA, 1999, p.107). Nesse sentido, os sujeitos são, portanto, resultado de um processo cultural e social que a escola produz e reproduz continuamente. Os estudos póscríticos questionam o poder ideológico da escola, contestando a ideia de identidades fixas, mostrando como o sujeito da modernidade tardia apresenta suas identidades móveis e desfragmentadas. 
A identidade plenamente unificada, completa, segura e coerente é uma fantasia. Ao invés disso, à medida em que os sistemas de significação e representação cultural se multiplicam, somos confrontados por uma multiplicidade desconcertante e cambiante de identidades possíveis, com cada uma das quais poderíamos nos identificar - ao menos temporariamente. (HALL, 2003, p. 13).

A inclusão dessas temáticas na escola pelo multiculturalismo permite desconstruir a tendência à homogeneização, ao padrão, dando ênfase ao reconhecimento da diferença, em um processo de confronto permanente e não ocultando o outro, por isso a importância de reconhecer a multiplicidade das identidades que estão presentes no espaço escolar, permitindo o diálogo e empatia em relação ao outro que tanto colabora e interfere nessa troca de construções do conhecimento e de nossas identidades. Para isso, o presente discurso permite desmitificar a noção sólida de uma única forma de masculinidade e feminilidade que perpetua um modelo de comportamento de acordo com o sexo, instituído pela sociedade. Dessa forma, os estudos culturais na perspectiva de gênero têm a função de nos fazer perceber "[...] os processos de produção cultural a partir também da participação (atual e histórica) de grupos que, socialmente marginalizados, não eram reconhecidos pelas suas contribuições à cultura moderna" (ADELMAN, 2006 , p. 1). Atualmente os grupos se apresentam de forma atuante e contestadora em espaços e discursos.

As construções mencionadas até agora se refletem de forma significativa nos corpos dos sujeitos, pois é neles que as representações ganham materialidade. As descrições normativas, naturalizadas e legitimadas pela biologia, demarcam espaço nos indivíduos através do seu corpo, ganhando representatividade e sentido. Quando esses padrões fogem da norma estabelecida, logo são questionados.

O indivíduo constrói a evidência de seus comportamentos como homem ou mulher, sem ter sempre a consciência disso, pois adquiriu o princípio desses comportamentos ao longo de sua infância, através da socialização, e sua confirmação depende do jogo comum da existência (LE BRETON, 2014, p. 19).

Podemos citar como exemplo de "natureza feminina" instituída pelo patriarcado, o corpo da mulher que é visto como frágil e detentor de sensibilidade e critérios que categorizam e fundamentam a maternidade, deixando a mulher à margem. Assim, pode-se afirmar que "[...] o olhar e o discurso masculino sexualizam o corpo das mulheres. $O$ instinto e o amor materno tornam-se mecanismos de controle da sexualidade feminina" (ARAUJO, 2009, p. 113). As noções que individualizamos de homem e mulher não são essências, são transmitidas, são construções de inteligibilidade do corpo através do social, são polaridades que foram instituídas. Percebe-se, através do contexto histórico, que não se trata de uma naturalidade, mas de algo instituído socialmente, em que aos homens foi designado o poder da razão e às mulheres o instinto da reprodução, estabelecidos através de seu corpo. Fica evidente que:

Os modos de ser e estar no mundo que se tornaram hegemônicos dizem respeito a modos como foram pensados e produzidos os corpos, os gêneros e as sexualidades, reduzidos a dimensões fragmentadas, aprisionadas e binárias. Generalizada e naturalizada, a heterossexualidade, inscrita no corpo, tornou-se referência em todos os lugares e para todos os indivíduos, alerta-nos Guacira Louro desde 1999. Essa forma de sexualidade invadiu os textos escolares e os 
procedimentos pedagógicos que visavam educar meninos e meninas, e ainda neles permanecem neste começo de século XXI (SILVA, 2014, p. 67).

Essa discussão remete a pensar corpo como construção sociocultural, considerando masculinidades e feminilidades e outras diversas formas relacionadas aos corpos biológicos, ao passo que não se pode pensar corpo descontextualizado de gênero.

Hoje, como outrora, a biologia é um capítulo do político. O sexo, assim como o corpo, é uma cristalização de significados sociais, inclusive em sua descrição, que não seria capaz de escapar a categorias de sentido e de valores. O corpo não determina mais a identidade, ele está a serviço dela (LE BRETON, 2014, p. 32).

Através desse contexto surge o desafio de articular o comum com o plural, a igualdade com a diferença, de promover debates sobre como se produzem os preconceitos, de qual deve ser a expressão da escola diante das diversas identidades, diferenças sexuais e de gênero dos sujeitos envolvidos nas relações escolares, enfatizando-se também suas intersecções com questões de classe e raça.

Vários problemas sociais decorrem do sexismo, heterossexismo e iniquidade de gênero, associados a outras desigualdades, e se refletem na escola: discriminações e violências, a gravidez na adolescência, a exploração/ desvalorização do trabalho das mulheres, doméstico e remunerado, entre os quais o docente, a omissão de paternidade e a decorrente sobrecarga das mães. E a escola participa direta e indiretamente, na ação ou omissão, da construção desses problemas e desigualdades, dando tratamento desigual a alunos e alunas e legitimando visões preconceituosas de mundo e sujeito (CARVALHO, 2010, p. 79).

O cotidiano escolar é influenciador, formador de opinião, discursivo, portanto, deve-se compreender a necessidade de inserir nos processos de ensino e aprendizagem práticas que projetem um currículo escolar para acompanhar o mundo contemporâneo que é cada vez mais heterogêneo. Coadunando com esse pensamento, Dias salienta:

A instituição escolar é um espaço privilegiado de socialização, nela recebe especial atenção o modo como os sujeitos, em relações sociais atravessadas por diferentes discursos, símbolos, representações e práticas, vão construindo suas identificações, (re)construindo seus lugares sociais, suas disposições, suas formas de ser e estar no mundo (DIAS, 2014, p. 64,65).

Percebe-se, assim, que os processos educativos estão relacionados à socialização, e é imprescindível a compreensão da análise de gênero na instituição escolar, visando à contribuição de comportamentos e práticas não-sexistas, aceitação da diversidade e tolerância ao outro. A partir desse pensamento a escola estará contribuindo para o questionamento da norma estabelecida, rompendo com uma história patriarcal que consolidou por muito tempo um currículo escolar androcêntrico e racista. Não optar por essa alternativa significa que a escola mantém a ordem dominante e naturaliza comportamentos de subordinação.

Isso não quer dizer que adotamos uma postura ingênua, utópica ou reducionista em relação às instituições de educação, já que compreendemos que elas não têm o poder, de eliminar práticas sexistas, mas podem, entretanto, assumir uma 
postura crítica, atenta e problematizadora em relação a suas práticas e componentes (OLIVEIRA; RAMOS; SALVA, 2011, p. 102).

A inclusão das temáticas na escola não está restringindo a ela o poder de modificar toda uma ordem social estabelecida historicamente, mas como um espaço propício à problematização dessas questões, dando-lhes visibilidade e questionando as atitudes que legitimam padrões binários mediante uma lógica sexista e discriminadora. Além de ser uma prática que deve estar presente na prática cotidiana, essas temáticas devem estar presentes no Projeto Político Pedagógico, no Currículo Escolar, nos Planos de Cursos, como registro da prática, como meta a ser seguida.

\section{CORPO, GÊNERO E SEXUALIDADE NO CURRÍCULO ESCOLAR}

É possível refletir como os estudos de corpo, gênero e sexualidades estão tão imbricados e presentes no contexto escolar, mesmo que de forma oculta, que ainda não tenham ganhado a relevância que devem ter. O cotidiano escolar está marcado pelas vertentes que moldam e legitimam a prática pedagógica, que controlam e segregam os sujeitos, mas, ao mesmo tempo, pode ser questionador e libertador.

Percebendo o Projeto Político Pedagógico como elemento integrador entre teoria e prática, sujeito e objeto, conhecimento e realidade, sua relevância social e pertinência para a instituição escolar, é de suma importância dialogar com pressupostos de uma educação transformadora e crítica, como a inclusão da perspectiva de gênero em sua metodologia.

O Projeto Político Pedagógico surgiu em um contexto histórico de transição, após duas décadas de regime militar no Brasil que controlou todas as instâncias dos órgãos públicos e também a escola. O movimento de democratização no país trouxe um longo desafio, ao propor romper as barreiras delimitadas pelo modelo de Estado intervencionista; uma dessas barreiras foi a gestão democrática do ensino público, principal característica desse instrumento norteador.

Somente muito mais tarde, em 1996, com a Lei de Diretrizes e Bases da Educação Nacional (Lei 9.394 de 20 de dezembro de 1996), todas as instituições de ensino passaram a ter a incumbência de elaborar e executar sua proposta pedagógica. Para isso deve ser assegurado que toda a comunidade escolar participe do processo, dando voz a todos os segmentos que compõem a escola no fazer ativo e vivo este instrumento.

A gestão democrática deve estar impregnada de uma certa atmosfera que se respira na escola, na circulação das informações, na divisão do trabalho, no estabelecimento do calendário escolar, na distribuição das aulas, no processo de elaboração ou de criação de novos cursos ou novas disciplinas, na formação de grupos de trabalho, na capacitação dos recursos humanos, etc. A gestão democrática é, portanto, atitude e método. A atitude democrática é necessária, mas não suficiente. Precisamos de métodos democráticos que atendam ao efetivo exercício da democracia. Ela também é um aprendizado, demanda tempo, atenção e trabalho (GADOTTI; ROMÃO, 1997, p.36).

Esse novo modelo instituído para a escola trouxe para seu espaço aqueles que antes estiveram excluídos do sistema público de ensino. A diversidade passou a compor seu quadro e logo surgiu a necessidade de adequação à realidade. Com o intuito de referenciar as escolas, o 
governo federal instituiu os Parâmetros Curriculares Nacionais, trazendo além dos conteúdos das disciplinas obrigatórias os temas transversais que permeiam o cotidiano escolar e são responsáveis pela construção de um cidadão crítico e atuante na sociedade.

O trabalho aqui exposto se propõe a apreender como um objeto de política viva da escola, logo de toda a comunidade é contemplada por esse documento dialógico e de construção permanente. Diante do exposto, percebe-se a necessidade de incluir nessa construção, objetivos que caracterizem a escola como um espaço democrático.

Além de compreender o processo histórico e questionar as construções mencionadas anteriormente, a valorização do diferente e o respeito às diversas formas de manifestação de identidades são perspectivas adotadas pelos estudos de gênero. Sendo a escola uma instituição que serve de palco para troca de experiências em que o diferente é tão intrínseco a ela, percebese o espaço educativo como um espaço formador de indivíduos críticos que respeitem o diferente, a partir de práticas que priorizem o plural, fundamentadas em um trabalho de gênero.

Mesmo com as mudanças que a Constituição Federal de 1988 ofereceu em defesa dos direitos, conforme inciso $V$ do art. 3․: "[...] sem preconceitos de origem, raça, sexo, cor, idade e quaisquer outras formas de discriminação" (BRASIL, 1988), a noção de gênero ainda ficou pouco definida para o campo da educação. No ano 2000, o Brasil assinou a "Declaração de Jomtien", documento elaborado na Conferência Mundial de Educação para Todos (Tailândia), do qual, entre as oito metas traçadas para a melhoria das condições de vida pela Organização das Nações Unidas, destacamos a promoção da igualdade entre os gêneros e o empoderamento das mulheres.

Esse tem sido um desafio contínuo a ser enfrentado pela instituição escolar que se propõe a assumir a responsabilidade da construção de um espaço que apoie a diversidade e tenha como necessidade priorizar a igualdade de condições, respeito entre todos os indivíduos, considerando os principais documentos que norteiam e legitimam o ensino e a proteção dos direitos humanos. Como destacado pelas autoras Viana e Unbehaum “[...] a elaboração dos PCNs, entre 1995 e 1997 teve por objetivo nortear os currículos do ensino fundamental e médio em todo território nacional, representando um importante passo na inclusão da perspectiva de gênero na educação". (VIANA; UNBEHAUM, 2006, p. 416)

Pensar essas temáticas no Projeto Político Pedagógico é uma forma de superar os silenciamentos que a falta de familiaridade com o tema e outras questões impedem de legitimar a escola como um espaço do plural; os Parâmetros Curriculares Nacionais são um amparo legislativo que o professor tem para tratar dessas questões em sua prática, portanto trazer as temáticas para um documento que tem por objetivo nortear sua prática é de suma importância para que possa facilitar ainda mais a inclusão no contexto pedagógico da sala de aula e de todos os espaços de vivência da escola.

\section{O OLHAR PARA DENTRO DA ESCOLA}

O ponto de partida inicial para a pesquisa foi apresentar a proposta para a direção da escola, descrevendo como seria feita análise e qual a contribuição para a escola. A direção mostrou-se acessível e indicou os trâmites legais para realização, como ofício de solicitação de acesso ao documento e descrição da pesquisa. Dessa forma, apresentamos as principais questões que motivaram a sua realização: A metodologia descrita no Projeto Político Pedagógico contempla 
os estudos de corpo, gênero e sexualidade? Qual o lugar dessas temáticas nesse documento? Como a escola percebe a diversidade?

O Projeto Político-Pedagógico é referente aos anos 2014/2016 e reelaborado após a troca de direção da escola, em janeiro de 2014 e foi reconstruído e aprovado pela comunidade escolar, obedecendo aos critérios de participação de todos. Na contracapa em destaque há o registro de uma frase de Paulo Freire:

\begin{abstract}
Planejar a prática significa ter uma ideia clara dos objetivos que queremos alcançar com ela. Significa ter um conhecimento das condições em que vamos atuar, dos instrumentos e dos meios que dispomos. Planejar a prática significa também saber com quem contamos para executá-la. (FREIRE, apud COLÉGIO ESTADUAL 17 DE MARÇO, 2014, p. 2).
\end{abstract}

A frase ilustrativa do Projeto revela o cerne do documento escolar como uma proposta de ação. Logo após a identificação do colégio, da equipe diretiva e do corpo docente, na apresentação a instituição revela sua concepção de PPP:

O Projeto Político Pedagógico representa para a Escola a sua organização administrativa, financeira e pedagógica que norteia suas atividades pedagógicas de forma a dar um rumo na resolução dos seus problemas educacionais, de infraestrutura, recursos humanos e materiais, na busca de uma melhoria no processo de ensino-aprendizagem (COLÉGIO ESTADUAL 17 DE MARÇO, 2014, p. 7).

Percebe-se, dessa forma, que o instrumento conduz a escola em questões materiais que envolvem estrutura física, condições para oferecer espaços para uma educação de qualidade, recursos lúdicos e tecnológicos, materiais que auxiliem o professor na sala de aula, fontes financeiras para manter seu funcionamento, ele também é subjetivo, pois, além de conduzir o trabalho organizacional, administrativo, financeiro ele também é pedagógico, direcionando o processo de ensino e aprendizagem. Daí a importância de incluir em sua perspectiva conduções que contemplem nas práticas ações que possam ir de encontro a um discurso que hierarquize e marginalize os envolvidos no processo, reconhecendo o espaço escolar como um espaço de vivência democrática que todos tenham voz, desfazendo os estereótipos que permeiam a prática pedagógica.

No tópico Pressupostos Teóricos, estão expostos os princípios em que o trabalho pedagógico será baseado, no qual se destaca: "Incentivar o aluno a pensar e se expressar livremente, preservando as defesas de interesse público" (COLÉGIO ESTADUAL 17 DE MARÇO, 2014 , p. 08). Mesmo trazendo a subjetividade da liberdade na expressão do aluno, percebe-se que há um limite quando, após a vírgula, ela traz o vocábulo "preservando"; convém então questionar: Que interesse público é esse? É o padrão cultural? São os discursos que a sociedade naturalizam?

Sabe-se que os discursos constituem o sujeito, produzindo os "[...] lugares a partir dos quais os sujeitos podem se posicionar [...]" (WOODWARD, 2000, p. 17) e as formas como ele deve se comportar de acordo com padrões instituídos de forma biológica. E a escola reflete e reproduz isso em seu discurso, normatizando os corpos a partir dessa determinação sexista. De acordo com Reis e Paraíso "[...] nessa produção das posições dos sujeitos pelos discursos, algumas são constituídas 
como normais e Inteligíveis e outras não (...) a partir de padrões estabelecidos culturalmente". (REIS; PARAÍSO, 2014, pp. 239-240).

A escola define como objetivo geral: "[...] proporcionar mudanças na Escola de forma que a mesma deixe de ser burocrata, tendo como fim à aprendizagem dos seus alunos, desenvolvendo neles, seu espírito crítico, participativo, criativo, tornando-o um cidadão ativo no seu meio" (COLÉGIO ESTADUAL 17 DE MARÇO, 2014, p 10). Essa concepção reflete que a instituição percebe o aluno como atuante e não como simples recebedor de conteúdo, pode-se considerar que essa percepção é positiva, pois o próprio aluno pode questionar práticas transgressoras que a escola possa exercer, diante de uma construção cultural a que ela está submetida como aparelho ideológico do estado na reprodução de ideais que inviabilizam a pluralidade. O colégio reforça sua intenção nas metas de atuação e apresenta sua prioridade: "[...] promover mudanças através de palestras, reuniões, debates e pesquisa” (COLÉGIO ESTADUAL 17 DE MARÇO, 2014, p 10).

Já na metodologia, no primeiro parágrafo do texto lê-se:

Na realidade atual, onde as pessoas estão acostumadas a conviver com a miséria e a exclusão social, cabe à escola, formadora de opiniões do cidadão do terceiro milênio, a tarefa de buscar as formas de construir uma sociedade de todos, onde a exclusão e a desigualdade sejam substituídas pela justiça e pela igualdade de oportunidades (COLÉGIO ESTADUAL 17 DE MARÇO, 2014, p. 7).

Mesmo que a escola mostre-se aberta, de forma geral, em algumas instituições ainda há um processo de exclusão, que embora sejam um espaço de socialização, os lugares são predeterminados pela rotina escolar em que características masculinas e femininas são priorizadas na prática, vinculadas a um processo normativo de escolarização dos corpos.

Embora se perceba o trabalho de socialização desenvolvido no cotidiano das instituições escolares, este é constituído de um processo de "doutrinação" do espaço/tempo pensado para atender as características masculinas e femininas dos sujeitos que constituem o cotidiano escolar. Formas de comportamento corporais, conteúdos disciplinares, currículos e linguagens nas práticas escolares permitem um controle no processo de escolarização, ditos como naturais (DIAS, 2014, p. 65).

Os estudos de gênero vêm também pressionar a escola a assumir sua posição como um espaço coletivo, sua condição de espaço público de embate dos problemas sociais, de acolhimento aos vulneráveis e aos marginalizados e promoção do respeito à diversidade.

O destaque dado pela escola ao seu projeto mencionado na metodologia pode indicar um avanço mesmo que de forma superficial favorecendo um aprofundamento de uma política de enfrentamento considerando a abordagem de gênero, das identidades sexuais, das minorias, na "igualdade de oportunidades" em que a instituição se percebe como um espaço apropriado para essa ação. Por esse motivo é uma discussão tão presente e necessária no contexto escolar, diante das diversas formas que a escola age na formação de indivíduos, como problematizadora do conhecimento e, logo, como um espaço de experiências significativas.

O contexto socioeconômico em que o colégio está localizado, apesar de ser caracterizado no documento como "relativamente bom", revela que o atendimento é direcionado para alunos carentes que vêm das comunidades vizinhas. É um desafio, portanto, para a instituição reinserir 
esses indivíduos na sociedade, modificando sua realidade, entendendo a educação como modificadora de uma realidade excludente em que grupos são segmentados de acordo com sua classe social. As principais limitações relatadas são as experiências familiares dos alunos, que, de acordo com o documento, vivem apenas com um salário mínimo mesmo com a grande de composição da família. Os pais, além de não ser alfabetizados, trabalham o dia todo o que dificulta o acompanhamento de seus filhos na escola, por isso a maioria dos alunos são mantidos pelos avós. Dessa forma, a escola tenta mediar os conflitos visando à transformação do quadro de ausência familiar.

A realidade em que a escola está inserida permite ainda mais que se contemple na sua prática e logo no documento que direciona essa prática, destaques para ações voltadas à temática da equidade de gênero, de inclusão da perspectiva da diversidade, para que os envolvidos nessa realidade compreendam como ocorre a hierarquização das relações sociais em nossa sociedade, através das relações de poder, proporcionando discussões pautadas em suas vivências, suscitando discussões, promovendo a educação em direitos humanos e valorização da diversidade.

No quesito Visão Estratégica, a escola destaca como seus valores a participação, igualdade, transparência, integração, a sua missão e visão de futuro. Nesse ponto iremos destacar a noção de igualdade relatada que "[...] todos somos iguais, não há distinção deste ou daquele, independente da formatura e cargo que ocupa" (COLÉGIO ESTADUAL 17 DE MARÇO, 2010, p. 16). É possível reconhecer uma visão reducionista de igualdade, tratando-se da subjetividade que é o trabalho pedagógico na promoção da igualdade e como espaço em que as minorias perpassam seu cotidiano e são fragilizadas pelas suas condições.

Merece ainda relevância o tópico Clima Escolar, em que afirma que não encontramos neste espaço "[...] discriminação de cor, raça, religião, classe social e etc., sendo todos tratados com igualdade" (COLÉGIO ESTADUAL 17 DE MARÇO, 2014, p. 16). Cabe aqui uma análise mais aprofundada do cotidiano escolar para perceber de que forma isso realmente reflete na sua realidade e nos discursos dos agentes escolares, pais, funcionários, professores e alunos principalmente, pois esta pesquisa limita-se, a princípio, em uma análise documental, mas, percebe-se que o Projeto Político Pedagógico avança muito ao trazer a perspectiva da diferença, aceitar o outro como é. Mas, é preciso pensar que dentro da escola as relações são relações de poder, consequentemente as relações entre professores e professoras, professores e alunos e as demais relações que permeiam a escola tendem a reproduzir situações e vivências de preconceito, discriminações e hierarquias que são vindouras das relações fora do espaço escolar; isso significa dizer que as experiências dos agentes escolares, familiares, profissionais tendem a influenciar as suas representações.

A partir do momento que a escola possibilita tais discussões, essas representações são problematizadas, visto que no documento da escola já tem essa preocupação, isso significa que a escola já começou a fazer um trabalho para pensar essas questões. Além disso, percebe-se que o as discriminações de gênero e identidades sexuais não são contempladas no momento em que a escola afirma que no cotidiano escolar não foram identificado casos de discriminações. Isso pode nos revelar que os agentes escolares não possuem familiaridade com as temáticas.

Em outra parte do documento, intitulada "Efetividade do Processo Ensino-Aprendizagem", afirma-se que o currículo é organizado e articulado com os Parâmetros Curriculares Nacionais, em nenhum momento é citado os temas transversais, e as discussões de corpo, gênero e sexualidades 
são ausentes no documento. Isso pode revelar o despreparo dos envolvidos na construção do Projeto Político Pedagógico, diante de uma formação discriminadora que não têm contemplado o discurso de corpo, gênero e sexualidade em seu currículo, o que pode tornar-se objeto de estudo de uma próxima publicação.

\section{CONSIDERAÇÕES FINAIS}

A partir de uma dedicada análise do documento, revela-se que as construções de gênero, corpo e sexualidade estão superficiais em um documento tão importante para a escola, mostrando que há muito que avançar na reformulação do direcionamento das práticas que priorizem uma formação para a diversidade.

É necessário que o currículo escolar possa destacar e dar visibilidade à equidade de gênero, aos grupos socialmente marginalizados e às mulheres, através da inserção desses aspectos nos objetivos que norteiam e direcionam as ações pedagógicas que desejam formar cidadãos para uma educação em sexualidade e gênero. Algumas ações governamentais têm chamado a atenção da escola para essa necessidade, no intuito de estimular a implementação desses documentos, envolvendo as temáticas na escola, capacitando os profissionais que a compõem para trabalhar sexualidade e gênero.

Ainda que seja um verdadeiro desafio trazer para o espaço escolar a introdução desses temas, é preciso rever a necessidade da disseminação da informação e da educação, como direito subjetivo do ser humano, para que se possa desenvolver uma postura de respeito à diversidade.

A escola não deve coadunar com a perpetuação de construção que normatizam as hierarquias baseadas nas concepções estereotipadas no binarismo masculino e feminino, mas viabilizar uma aproximação aberta e empática com o outro, questionando o universalismo numa ótica intercultural. E isso deve está presente nos documentos que legitimam sua prática.

\section{REFERÊNCIAS BIBLIOGRÁFICAS}

1. ARAUJO, Janaina Rodrigues. Relações de gênero na educação infantil: Questionamentos acerca da reduzida presença de homens na docência. In: Discutindo relações de gênero na escola: reflexões e propostas para a ação docente. TEIXEIRA, Adla Betsaida Martins; DUMONT, Adilson (org.). Araraquara (SP): Junqueira \& Marin, 2009.

2. ADELMAN, Miriam. Estudos culturais e estudos de gênero: Entendendo os olhares. Cadernos da Escola de Comunicação. № 04; 2006. Disponível em: <http://revistas. facbrasil.edu.br/ca dernoscomunicacao/index.php/comunicacao/article/view/40/40>. Acesso em: 13 mai. 2015

3. BOURDIEU, Pierre. A dominação masculina. Rio de Janeiro: Bertrand Brasil, 1999.

4. BRASIL. Constituição (1988). Constituição da República Federativa do Brasil. Brasília, DF: Imprensa Oficial, 2001.

5. , Lei n. 9.394, de 20 de dezembro de 1996. Estabelece as diretrizes e bases da educação nacional. Diário Oficial da União Brasileira, DF, 23 dez. 1996ạ p. 27894. Disponível em: <www.senado.gov.br/legbras>.

6.

Ministério da Educação e do Desporto. Secretaria de Educação Fundamental. Parâmetros curriculares nacionais: ensino fundamental. Brasília, DF:MEC/SEF, 
1997. Disponível em: <www.mec.goc.br/sef/sef/pcn.shtm>.

7. CARVALHO, Maria Eulina Pessoa de. Gênero é um conceito complexo e de difícil sensocomunização. Considerações a partir de uma experiência de formação docente. R. Est. Pesq. Educ. Juiz de Fora, v. 12, n. 2, jul./dez. 2010.

8. COlÉGIO ESTAdUAL “17 DE MARÇO”. Projeto Político Pedagógico. Aracaju, 2014.

9. CRUZ, Maria Helena Santana Cruz. Gênero e diversidade na escola. (Aula Inaugural: - CURSO DE APERFEIÇOAMENTO EM GÊNERO E DIVERSIDADE NA ESCOLA). CESAD/NUPAT/UFS, 2014.

10. DENZIN, Norman K. O planejamento da pesquisa qualitativa: teorias e abordagens. Porto Alegre: Artmed, 2006.

11. DIAS, Alfrancio Ferreira. Representações sociais de Gênero no trabalho docente: sentidos e significados atribuídos ao trabalho e a qualificação. Vitória da Conquista (BA): EDUESB, 2014.

12. FOUCAULT, Michel. El sujeto y el poder. Revista Mexicana de Sociologia, año L, n.3, jul.-sep. 1988.

13. GADOTTI, M.; ROMÃO, J. Autonomia da escola: princípios e propostas. São Paulo: Cortez, 1997.

14. HALL, Stuart. A identidade cultural na pós-modernidade. Rio de Janeiro: DP\&A, 1999.

15. Da diáspora: identidades e mediações culturais. Belo Horizonte: UFMG, 2003.

16. LE BRETON, David. Corpo, gênero, identidade. In: FERRARI, Anderson (org.). Corpo, gênero e sexualidade. Lavras (MG): UFLA, 2014.

17. LOURO, Guacira Lopes. Gênero, sexualidade e educação: uma perspectiva pós-estruturalista. Petrópolis: Vozes, 2010.

18. OLIVEIRA, Keila de; RAMOS, Ethiana Sarachin da Silva; SALVA, Sueli. Relações de gênero e educação. Revista Sociais e Humanas. Centro de Ciências Sociais e Humanas - Universidade Federal de Santa Maria, Rio Grande do Sul, Brasil. v. 24, n. 2, 2011.

19. REIS, Cristina d'Ávila; PARAISO, Marlucy Alves. Normas de gênero em um currículo escolar: a produção dicotômica de corpos e posições de sujeito meninos-alunos. Estudos Feministas, v. 22, n.1, pp. 237-256, 2014.

20. SCOTT, J. Gênero: uma categoria útil de análise histórica. Educação e Realidade. Vol. 20 (2), jul./dez. 1995

21. SILVA, Tomaz Tadeu da. Documentos de identidade: uma introdução às teorias do currículo. Belo Horizonte: Autêntica, 1999.

22. SILVA, Elenita Pinheiro de Queiroz. Entremeando corpos, sexualidades, gêneros e educação escolar. In: FERRARI, Anderson (org.). Corpo, gênero e sexualidade. Lavras (MG): UFLA, 2014.

23. VIANA, Claudia; UNBEHAUM, Sandra. Gênero na educação básica: quem se importa? Uma análise de documentos de políticas públicas no Brasil. Educ. Soc., Campinas, Vol. 27, n. 95, p. 407-428, maio/ago. 2006. Disponível em <www.cedes.unicamp.br>. Acesso em: 13 mai.2015

24. WOODWARD, Kathryn. Identidade e diferença: uma introdução teórica e conceitual. In: SILVA, Tomaz Tadeu da. Identidade e diferença: a perspectiva dos estudos culturais.7. ed. Petrópolis (RJ): Vozes, 2007. 